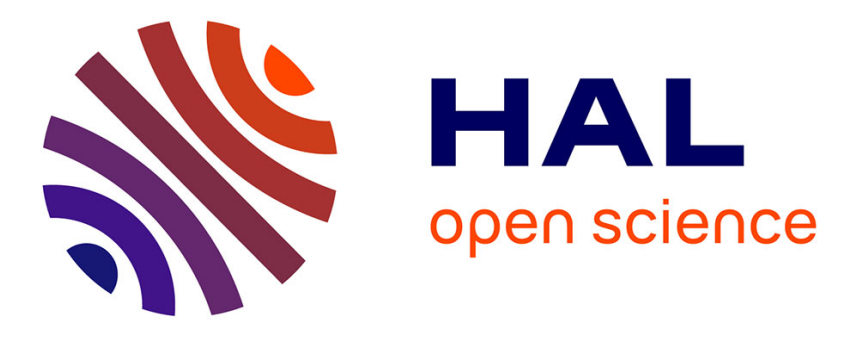

\title{
Combustion of silane-nitrous oxide-argon mixtures: Analysis of laminar flame propagation and condensed products
}

R. Mével, K.P. Chatelain, Y. He, Simon Lapointe, D. A. Lacoste, M Allix, Nabiha Chaumeix, C.-E. Paillard

\section{To cite this version:}

R. Mével, K.P. Chatelain, Y. He, Simon Lapointe, D. A. Lacoste, et al.. Combustion of silane-nitrous oxide-argon mixtures: Analysis of laminar flame propagation and condensed products. Proceedings of the Combustion Institute, 2021, Proceedings of the Combustion Institute, 38 (2), pp.2235-2245. 10.1016/j.proci.2020.06.381 . hal-03098707

\section{HAL Id: hal-03098707 https://hal.science/hal-03098707}

Submitted on 5 Jan 2021

HAL is a multi-disciplinary open access archive for the deposit and dissemination of scientific research documents, whether they are published or not. The documents may come from teaching and research institutions in France or abroad, or from public or private research centers.
L'archive ouverte pluridisciplinaire HAL, est destinée au dépôt et à la diffusion de documents scientifiques de niveau recherche, publiés ou non, émanant des établissements d'enseignement et de recherche français ou étrangers, des laboratoires publics ou privés. 
See discussions, stats, and author profiles for this publication at: https://www.researchgate.net/publication/343140753

\section{Combustion of Silane-Nitrous Oxide-Argon Mixtures: Analysis of Laminar Flame Propagation and Condensed Products}

Article in Proceedings of the Combustion Institute - July 2020

DOI: 10.1016/j.proci.2020.06.381

\section{CITATIONS}

2

8 authors, including:

R. Mével

Tsinghua University

134 PUBLICATIONS 703 CITATIONS

SEE PROFILE

7.7. Yizhuo $\mathrm{He}$

1. Tsinghua University

29 PUBLICATIONS 104 CITATIONS

SEE PROFILE

Some of the authors of this publication are also working on these related projects:

Project Ignition from localized hot surfaces View project

Project Transparent (glass)-ceramics View project
READS

78

Karl Chatelain

King Abdullah University of Science and Technology

29 PUBLICATIONS 95 CITATIONS

SEE PROFILE

Simon Lapointe

Lawrence Livermore National Laboratory

30 PUBLICATIONS 252 CITATIONS

SEE PROFILE 


\title{
Combustion of Silane-Nitrous Oxide-Argon Mixtures: Analysis of Laminar Flame Propagation and Condensed Products
}

\author{
R. Mével ${ }^{\mathrm{a}, \mathrm{b}, \mathrm{c}}$, K.P. Chatelain ${ }^{\mathrm{d}}$, Y. He $\mathrm{He}^{\mathrm{a}, \mathrm{b}, \mathrm{c}}$, S. Lapointe ${ }^{\mathrm{e}}$, D.A. Lacoste ${ }^{\mathrm{d}}$, M. Allix ${ }^{\mathrm{f}}$, N. Chaumeix ${ }^{\mathrm{g}}$, C.-E. \\ Paillard ${ }^{\mathrm{g}, \mathrm{h}}$ \\ ${ }^{a}$ Center for Combustion Energy, Tsinghua University, Beijing, China \\ ${ }^{b}$ School of Vehicle and Mobility, Tsinghua University, Beijing, China \\ ${ }^{c}$ State Key Laboratory for Automotive Safety and Energy, Tsinghua University, Beijing, China \\ ${ }^{d}$ King Abdullah University of Science and Technology (KAUST), Clean Combustion Research Center (CCRC), Thuwal, Saudi Arabia \\ ${ }^{e}$ Lawrence Livermore National Laboratory, Livermore, USA \\ ${ }^{f}$ Conditions Extrêmes et Matériaux: Haute Température et Irradiation, CNRS-CEMHTI, Orléans, France \\ ${ }^{g}$ Institut de Combustion, Aérothermique, Réactivité et Environnement, CNRS-ICARE, Orléans, France \\ ${ }^{h}$ Université d'Orléans, Orléans, France
}

\begin{abstract}
The laminar burning rate, the explosion peak pressure, and the pressure rise coefficient have been measured for the first time for silane-nitrous oxide-argon mixtures using the spherically expanding flame technique in a constant volume combustion chamber. For these three parameters, the values obtained were higher than for hydrogen-nitrous oxide-argon and typical hydrocarbon-based mixtures. A maximum burning rate of $1800 \mathrm{~g} / \mathrm{m}^{2} \mathrm{~s}$ was measured at $101 \mathrm{kPa}$, whereas under similar conditions, a maximum burning rate around $950 \mathrm{~g} / \mathrm{m}^{2}$ s has been reported for hydrogen-nitrous oxide-argon mixtures. To better understand the chemical dynamics of flames propagating in $\mathrm{SiH}_{4}-\mathrm{N}_{2} \mathrm{O}-\mathrm{Ar}$ mixtures, a detailed reaction model from the literature was improved using collision limit violation analysis and updated thermodynamic properties calculated with a high-level ab initio approach. The reaction model predicts the burning rate within $14 \%$ on average but demonstrates error close to $50 \%$ for the richest mixtures. The chemistry of the H-O-N system is important under all the conditions presently studied. The chemistry of the Si-H-O-N system demonstrates an increasing importance under rich conditions. In particular, the reactions (i) forming $\mathrm{SiO}_{x}(\mathrm{~s})$; (ii) describing the interaction of $\mathrm{Si}$-species with $\mathrm{N}_{2} \mathrm{O}$; and (iii) involving silicon hydrides, have an important role for the heat release dynamics. The condensed combustion products formed in the silane-nitrous oxide-argon flames were sampled and characterized using electron micrograph, electronic diffraction, energy-dispersive spectroscopy, and X-ray powder diffraction. For all equivalence ratios, silica spherical particles with a mean diameter in the range 200-300 $\mathrm{nm}$ were observed. In addition, for mixtures with $\Phi \geq 2.2$, silicon nanowires were formed. X-ray diffraction experiments showed that the silicon nanowires are composed of metal silicon characterized by a cubic structure (lattice parameter: $a=5.425 \AA$ ) with the $\mathrm{Fm}-3 \mathrm{~m}$ space group.
\end{abstract}

Keywords:

Silane, Laminar flame speed, Expanding flame, Silica particle, Silicon nanowire

Email address: mevel@mail.tsinghua.edu.cn (R. Mével) 


\section{Introduction}

Silane $\left(\mathrm{SiH}_{4}\right)$ is a specialty gas widely employed in the semi-conductor and electronic component manufacturing industry [1]. Mixed with an oxidant such as nitrous oxide $\left(\mathrm{N}_{2} \mathrm{O}\right)$, silane can lead to the formation of insulating thin films of silicon oxide which protect the semi-conductors and electronic components [2]. Several studies on $\mathrm{SiH}_{4}$ $\mathrm{N}_{2} \mathrm{O}$ mixtures have mainly focused on the silica film growth rate under chemical vapor deposition conditions $[2,3]$. In these studies, performed either at atmospheric pressure or below, the temperature was below $1000 \mathrm{~K}$. A number of gasphase chemical kinetics studies related to $\mathrm{SiH}_{4}$ $\mathrm{N}_{2} \mathrm{O}$ mixtures have been performed. Becerra et al. [4] and Votintsev et al. [5] measured the rate constant of $\mathrm{SiH}_{2}+\mathrm{N}_{2} \mathrm{O}=\mathrm{H}_{2} \mathrm{SiO}+\mathrm{N}_{2}$ in the temperature ranges 295-747 $\mathrm{K}$ and 1400-1800 K, respectively. While Votintsev et al. derived their rate constant from chemiluminescence of $\mathrm{H}_{2} \mathrm{SiO}^{*}$, Becerra et al. employed direct laser absorption spectroscopy of $\mathrm{SiH}_{2}$ at $579 \mathrm{~nm}$. The chemical dynamics of $\mathrm{Si}, \mathrm{N}$, and $\mathrm{O}$ atoms in reflected-shock heated $\mathrm{SiH}_{4}-\mathrm{N}_{2} \mathrm{O}-\mathrm{Ar}$ mixtures were studied by Mick and Roth [6] and by Mevel et al. [7] using atomic resonance absorption spectroscopy (for $\mathrm{N}$ and $\mathrm{O}$ ) and direct absorption spectroscopy (for $\mathrm{Si}$ ). To our knowledge, only two studies have been performed to characterize the combustion properties of $\mathrm{SiH}_{4}$ $\mathrm{N}_{2} \mathrm{O}$ mixtures. Horiguchi et al. [8] have measured the flammability limits of silane-nitrogen oxides mixtures. For $\mathrm{NO}, \mathrm{NO}_{2}$, and $\mathrm{N}_{2} \mathrm{O}$ as oxidant, they reported flammability ranges of 2.1492.7, 7.08-95.8, 1.9-87.1\% of $\mathrm{SiH}_{4}$, respectively, for atmospheric pressure and ambient temperature. Thomas et al. [9] investigated the deflagration to detonation transition in silane-nitrous oxide mixtures (equivalence ratio: $\Phi=1.11$ ) diluted with nitrogen $\left(\mathrm{X}_{N 2}=0-0.925\right)$. Pressure traces typical of detonation were observed for $\mathrm{X}_{N 2} \leq 0.62$, at $\mathrm{P}_{1}=101 \mathrm{kPa}$ and $\mathrm{T}_{1}=283 \mathrm{~K}$. Whereas many laminar flame speed studies have been performed for hydrocarbon-based mixtures [10], very few have been made for silicon-containing compounds. Despite the pyrophoric nature of silane, Tokuhashi et al. [11] were able to measure the burning velocity of various $\mathrm{SiH}_{4}-\mathrm{O}_{2}-\mathrm{N}_{2}$ mixtures using a specially designed burner. They reported a burning velocity of $55 \mathrm{~cm} / \mathrm{s}$ for a mixture of $2 \%$ of $\mathrm{SiH}_{4}$ in air. Using the constant volume explosion method, Chao et al. [12] measured the flame speed of trichlorosilane, trimethylchlorosilane, methyldichlorosilane, dimethylchlorosilane, and tetramethylsilane, in air. At atmospheric pressure and ambient temperature, the fastest flame was observed for a rich $(\Phi=1.4)$ trichlorosilane-air mixture, with a flame speed of $124 \mathrm{~cm} / \mathrm{s}$. To the best of our knowledge, no data on the laminar flame speed nor on the explosion parameters of $\mathrm{SiH}_{4}-\mathrm{N}_{2} \mathrm{O}$ mixtures are available in the literature. In addition, the nature of the condensed combustion products has not been studied under flame conditions for these mixtures whereas Babushok et al. [13] showed that the formation of condensed combustion products was a dominant process for laminar flame propagation in $\mathrm{SiH}_{4}-\mathrm{O}_{2}$ mixtures. Because severe accidents have been attributed to silane-nitrous oxide mixtures [14], the determination of fundamental combustion properties, such as the laminar flame speed, the explosion peak pressure, and the pressure rise coefficient, is of primary importance to ensure their safe usage.

In the present study, we seek at (i) studying experimentally and numerically the laminar flame speed of silane-nitrous oxide-argon mixtures; (ii) determining the explosion parameters of these mixtures; and (iii) characterizing the condensed products formed during the combustion process.

\section{Materials and methods}

\subsection{Experimental approach}

The combustion vessel employed is made of stainless steel and has a spherical geometry with $250 \mathrm{~mm}$ inner diameter. Two opposite quartz windows, $70 \mathrm{~mm}$ in diameter and $30 \mathrm{~mm}$ thick, enable flame visualization using a Z-type schlieren arrangement. To protect the quartz windows from the impact of hot silica particles formed in the silane-based flame, glass plates were placed onto the main windows. Two high-speed cameras (Kodak and Photron), with a maximum framing rate of $24,000 \mathrm{fps}$ were employed to record the flame propagation. Ignition was achieved by focusing the beam of a pulsed Nd-YAG laser onto a thin molybdenum electrode. Figure 1 shows typical examples of flame propagation in $\mathrm{SiH}_{4}-\mathrm{N}_{2} \mathrm{O}$-Ar mixtures with different $\Phi$. The vessel pressure was measured using a Kistler piezo-electric pressure sensor (uncertainty of $\pm 3 \%$ ). During the period of the flame speed measurement, the pressure increase was below $2 \%$ of $P_{1}$. An in-house Matlab script, see [15], was employed to obtain the temporal evolution of the flame radius $\left(R_{f}\right)$. The resulting $R_{f}=\mathrm{f}(\mathrm{t})$ data were used to extract $S_{b}^{0}$, the unstretched flame speed with respect to the burned gas. The Linear Curvature (LC)

$$
S_{b}=S_{b}^{0}-2\left(S_{b}^{0} L_{B}\right) / R_{f},
$$

and Non-linear Quasi-steady (NQ)

$$
\ln \left(S_{b}\right)=\ln \left(S_{b}^{0}\right)-2\left(S_{b}^{0} L_{B}\right) /\left(R_{f} S_{b}\right),
$$


equations were employed, respectively for mixtures with low and high Lewis numbers (or negative and positive Markstein length $\left(L_{B}\right)$ ), see [16]. In Eq. 1 and 2, $S_{b}$ is the stretched flame speed with respect to the burned gas. By dividing $S_{b}^{0}$ by the expansion ratio $\left(\sigma=\rho_{u} / \rho_{b}\right.$, where $\rho_{u}$ and $\rho_{b}$ are the unburned and burned gas densities), the unstretched laminar flame speed with respect to the unburned gas, $S_{u}^{0}$, was obtained. The difficult preparation and handling of silane-based mixtures led to an uncertainty on $S_{u}^{0}$ of $\pm 15 \%$ for lean and rich mixtures, and of $\pm 10 \%$ around stoichiometry. This high uncertainty is due to (i) the difficulty in precisely controlling $X_{\mathrm{SiH}_{4}}$ because of a small dead-volume which could not be suppressed in the pipeline (see next paragraphs); (ii) the reduced image quality induced by the glass plates put onto the quartz windows; (iii) the uncertainty on $\sigma$; and (iv) the impact of radiation by the condensed combustion products.

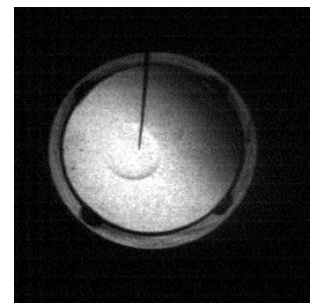

$\mathrm{t}=5.11 \mathrm{~ms}$

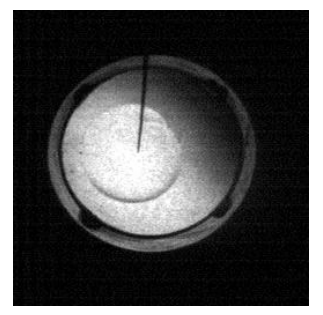

$\mathrm{t}=8.89 \mathrm{~ms}$

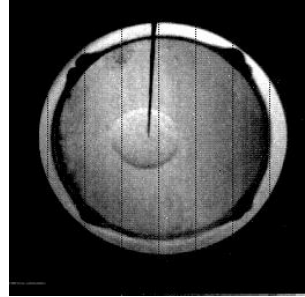

$\mathrm{t}=1.27 \mathrm{~ms}$

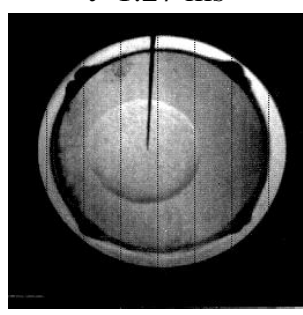

$\mathrm{t}=1.93 \mathrm{~ms}$ (a): $\Phi=0.31$

(b): $\Phi=1.5$

Figure 1: Schlieren images of flames in $\mathrm{SiH}_{4}-\mathrm{H}_{2}-\mathrm{N}_{2} \mathrm{O}-\mathrm{Ar}$ mixtures. $\mathrm{X}_{A r}=0.6 ; \mathrm{T}_{1}=300 \mathrm{~K} ; \mathrm{P}_{1}=51 \mathrm{kPa}$.

The following experimental procedure was employed to prepare the mixtures. After vacuuming the vessel to below $2 \mathrm{~Pa}$, the mixtures were prepared using the partial pressure method. All gases were pure and from research-grade. The dilution by Ar was $60 \%$, and $\Phi$ was in the range 0.3-2.6. The initial temperature was between 296 and 305 $\mathrm{K}$, and the pressure was 51 or $101 \mathrm{kPa}$. $\Phi$ was defined using

$$
\mathrm{SiH}_{4}+4 \mathrm{~N}_{2} \mathrm{O}=\mathrm{SiO}_{2(s)}+2 \mathrm{H}_{2} \mathrm{O}+4 \mathrm{~N}_{2} \text {. }
$$

Because silane is pyrophoric, the filling line could not be vacuumed after silane introduction in the vessel. Consequently, the desired silane pressure was reached by introducing successive small amounts. The residual silane in the pipeline was flushed out using several streams of nitrogen. This arrangement enabled to decrease the silane concentration below its lower flammability limit and safely evacuate it through a $1 \mathrm{~mm}$ in diameter hole to avoid flash back. Following each experiments, the spherical bomb was opened and the solid particles formed during combustion were removed from the electrode, the walls, and the windows.

\subsection{Particle sampling and analysis}

After evacuation of the gaseous combustion product, the vessel was put at atmospheric pressure and opened. The condensed products formed a powder whose amount increases with $\Phi$. Part of the powder was sampled using a square stainless steel plate $(2 \times 2 \mathrm{~cm})$ maintained on the combustion vessel inner wall using a magnet. As the flame touched the wall, a layer of powder was deposited onto the plate. Some of the powder was also collected using a metal spatula and placed in small glass tubes. The samples were placed in a desiccated argon bath to avoid contamination.

Bright-field transmission electron microscope (TEM) images were obtained using a Philips CM20 instrument operating at $200 \mathrm{kV}$. The samples were finely crushed in ethanol, and then a drop of the solution was deposited onto a carboncoated copper grid. Selected area electron diffraction (SAED) patterns, and energy-dispersive spectroscopy (EDS) were also performed with this facility. X-ray powder diffraction (XRPD) spectra were recorded with a Bruker D8 Advance Bragg-Brentano diffractometer $(\mathrm{Cu}-\mathrm{K} \alpha$ radiation) equipped with a Linear Vantec detector over the $10-110^{\circ}(2 \theta)$ angular range with a $0.032^{\circ}$ step size.

\subsection{Modeling approach}

The detailed kinetic scheme used was an updated version of the reaction model of Mevel et al. $[7,17]$. It is composed of 86 species and 425 reactions. It combines the reactions from [18] for the $\mathrm{H}-\mathrm{O}-\mathrm{N}$ system and from several studies [13, 1921] for the silicon-containing species. The interactions between the $\mathrm{Si}$-compounds and the $\mathrm{NO}_{x}$ come from Mick et al. [6, 22] and from Becerra et al. [4]. The formation of silicon-containing condensed combustion products, $\mathrm{SiO}(\mathrm{s})$ and $\mathrm{SiO}_{2}(\mathrm{~s})$, is described using the reaction pathways proposed by Suh et al. [23]. Some of the thermodynamic data were updated based on calculations performed using the high theory composite G4 method. Reaction rates above the collision limit were corrected. 
The transport properties were taken from Konnov [24] for the H-N-O system. For the Si-compounds, the transport properties were taken from Donovan et al. [25] or calculated using the semi-empirical relationships implemented in FlameMaster [26]. Further details about the reaction model are available in Chatelain et al. [27].

Cantera [28] was employed to perform adiabatic constant pressure, constant enthalpy (CP) and constant volume, constant internal energy $(\mathrm{CV})$ equilibrium calculations. Three cases were considered: (i) all species were treated as gases and $\mathrm{SiO}_{1,2}(\mathrm{~s})$ were the final products; (ii) all species were treated as gases and $\mathrm{SiO}_{1,2}(\mathrm{~g})$ were the final products; and (iii) all species were treated as gases except $\mathrm{SiO}_{1,2}$ (s) which were considered as solids. The difference between case (i) and case (ii) corresponds to a difference in thermodynamic properties between the final products $\mathrm{SiO}_{1,2}(\mathrm{~s})$ and $\mathrm{SiO}_{1,2}(\mathrm{~g})$. The difference between case (i) and case (iii) corresponds to the different phases (gas or condensed) used to describe $\mathrm{SiO}_{1,2}(\mathrm{~s})$. The flame speed simulations were performed using the LLNL code [30] with the mixture-averaged diffusion model and Soret effect. The number of grid points was kept above 1000 to ensure grid-independent results. All species were treated as gases because this code, like other flame speed codes such as those available in Chemkin or Cantera, do not describe multiphase media.

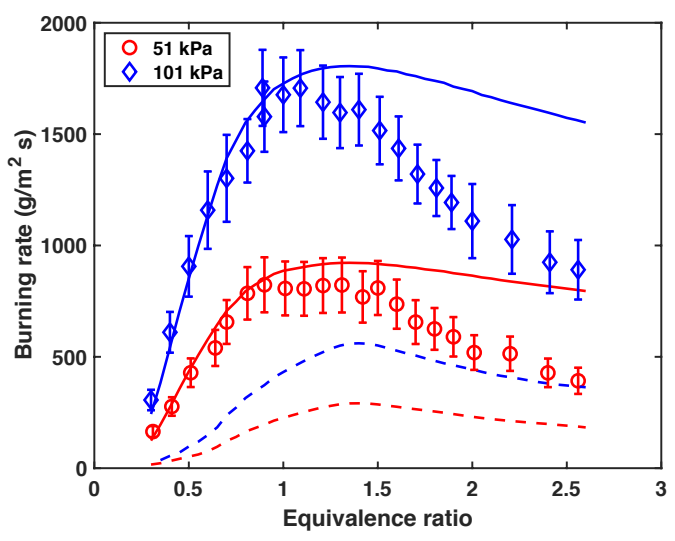

Figure 2: Experimental and calculated laminar burning rate for $\mathrm{SiH}_{4}-\mathrm{N}_{2} \mathrm{O}$-Ar mixtures. $\mathrm{X}_{A r}=0.6 ; \mathrm{T}_{1}=300 \mathrm{~K}$. Solid and dashed lines: predictions with and without $\mathrm{SiO}_{1,2}(\mathrm{~s})$ formation.

\section{Results and discussion}

\subsection{Combustion properties}

Figure 2 shows the experimental laminar burning rate $\left(S_{u}^{0} \times \rho_{u}\right)$ along with the model predictions. Laminar burning rate was plotted rather than $S_{u}^{0}$ to avoid the overlap of the data obtained at $\mathrm{P}_{1}=51$ and $101 \mathrm{kPa}$. The maximum burning rate measured is on the order of $1800 \mathrm{~g} / \mathrm{m}^{2} \mathrm{~s}$ at $101 \mathrm{kPa}$, which is significantly larger than that of hydrogennitrous oxide mixtures in the same conditions for which a maximum burning rate around $950 \mathrm{~g} / \mathrm{m}^{2}$ $\mathrm{s}$ was found [15]. The reaction model reproduces the experimental data within $14 \%$ on average but the error reaches $48 \%$ at $\Phi=2.6$ and $P_{1}=51 \mathrm{kPa}$. These discrepancies might be partly related to radiative heat losses which are not included in the simulations and are likely increasingly important as silane content increases. Ngai et al. [1] reported 3.5 to 5 times higher radiative heat flux for silaneair than for ethylene-air diffusion jet flames. As $\Phi$ increases, the contribution of the reactions involving $\mathrm{Si}$-species increases. Thus, the large difference between the experimental and calculated $S_{u}^{0}$ for the rich mixtures could also be due to missing chemical pathways or inadequate reaction rates. It is noted that many rate constants available for the reactions of silicon-species were estimated in previous studies [29] but never measured nor calculated. In Fig. 2, the dashed lines correspond to the model predictions when considering $\mathrm{SiO}_{1,2}(\mathrm{~g})$ as the final products. In this case, the burning rate is much lower, 4.5 times on average, than if $\mathrm{SiO}_{1,2}(\mathrm{~s})$ are taken as the final products. In accordance with the study of Babushok et al. [13], it is concluded that the formation of the condensed $\mathrm{SiO}_{x}$ products is of primary importance for flame propagation in silane-based mixtures. This aspect also leads to a larger uncertainty on the calculated flame speed since the precise nature and composition of the condensed products is not known from previous studies.

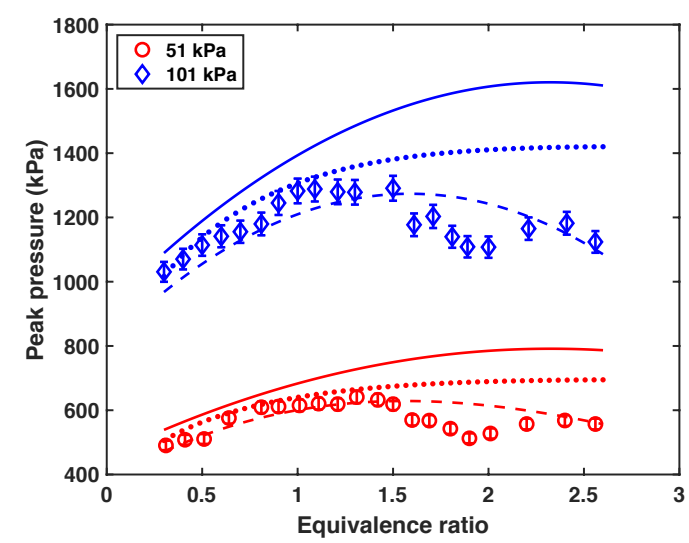

Figure 3: $\mathrm{CV}$ peak pressure for $\mathrm{SiH}_{4}-\mathrm{N}_{2} \mathrm{O}-\mathrm{Ar}$ mixtures. $\mathrm{X}_{A r}=0.6 ; \mathrm{T}_{1}=300 \mathrm{~K}$. Solid, and dotted lines are respectively the calculated $\mathrm{P}_{\text {max }}$ obtained when considering $\mathrm{SiO}_{1,2}(\mathrm{~s})$ as gaseous and condensed species. The dashed line is the calculated $\mathrm{P}_{\max }$ obtained when considering $\mathrm{SiO}_{1,2}(\mathrm{~g})$ as the final products.

Figure 3 shows the experimental peak pressure during the constant volume silane explosion as well as the corresponding $\mathrm{CV}$ calculations. The peak pressures are on the order of ten times $\mathrm{P}_{1}$, 
which is higher than typically observed for hydrocarbons combustion in air [31]. It is noted that a second peak of $\mathrm{P}_{\max }$ seems present around $\Phi=2.4$. It might be related to a change of composition of the combustion products which is discussed in the next section. When considering $\mathrm{SiO}_{1,2}(\mathrm{~s})$ as gases, the difference between the experimental and the calculated peak pressure increases from less than $10 \%$ for lean mixtures, to more than $40 \%$ for rich mixtures. When considering $\mathrm{SiO}_{1,2}(\mathrm{~s})$ as condensed species, the difference decreases to $3 \%$ at $\Phi=0.3$ and to $25 \%$ at $\Phi=2.56$. The CV explosion peak pressure calculated when neglecting the formation of $\mathrm{SiO}_{1,2}(\mathrm{~s})$ agrees within $5 \%$ with the experimental data.

We employed the method of [32] to determine the experimental pressure rise coefficient $\left(K_{g}\right)$ which is defined as

$$
K_{g}=(d P / d t)_{\max } V^{1 / 3},
$$

where $V$ is the volume of the combustion vessel. The uncertainty on $K_{g}$ is $\pm 12 \%$. The normalization of $(d P / d t)_{\max }$ using the $V^{1 / 3}$ enables future comparison with data obtained on a different experimental set-up. Figure 4 shows the evolution of $K_{g}$ as a function of $\Phi$ at $\mathrm{P}_{1}=51$ and $101 \mathrm{kPa}$. Maximum $K_{g}$ is approximately 80 and $220 \mathrm{MPa} \mathrm{m} / \mathrm{s}$, respectively for $\mathrm{P}_{1}=51$ and $101 \mathrm{kPa}$. A $K_{g}$ of 75 $\mathrm{MPa} \mathrm{m} / \mathrm{s}$ was reported for a lean silane-air mixture (3.7\% $\mathrm{SiH}_{4}$ in air) [33].

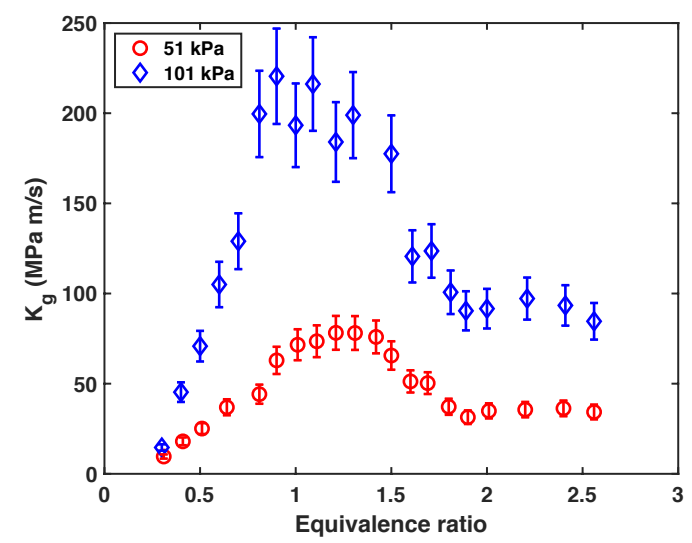

Figure 4: $K_{g}$ for $\mathrm{SiH}_{4}-\mathrm{N}_{2} \mathrm{O}-\mathrm{Ar}$ mixtures. $\mathrm{X}_{A r}=0.6 ; \mathrm{T}_{1}=300 \mathrm{~K}$.

To understand the laminar flame dynamics in $\mathrm{SiH}_{4}-\mathrm{N}_{2} \mathrm{O}-\mathrm{Ar}$ mixtures, we analyzed the rate of production $(\mathrm{OH}$ and $\mathrm{H}$ ROP), Fig. 5, the heat release rate per reaction (HRR), Fig. 6, and the sensitivity coefficient on $S_{u}^{0}$, Fig. 7. The sensitivity coefficient for reaction $i$ was defined as $C_{S}(i)=$ $\left(k_{i} / S_{u}^{0}\right)\left(\partial S_{u}^{0} / \partial k_{i}\right)$ with $k$ being the rate constant. We have integrated the ROP and HRR over the domain used to calculate $S_{u}^{0}$. All these parameters were normalized with respect to the highest absolute value. In Fig. 5 to 7, the reactions were classi- fied as: (i) reactions belonging to the $\mathrm{H}-\mathrm{O}-\mathrm{N}$ system; (ii) reaction producing $\mathrm{SiO}_{x}$ (s) species; (iii) the oxidation reactions for Si-species; and (iv) pyrolysis reactions for silicon hydrides.

In group (i), the most important reactions are $R_{1}$ : $\mathrm{N}_{2} \mathrm{O}+\mathrm{H}=\mathrm{N}_{2}+\mathrm{OH}$ and $R_{10}: \mathrm{N}_{2} \mathrm{O}(+\mathrm{M})=\mathrm{N}_{2}+\mathrm{O}(+\mathrm{M})$. $\mathrm{R}_{1}$ is a dominant pathway for $\mathrm{OH}$ and $\mathrm{H} \mathrm{ROP}$, one of the most important reaction in term of heat release, and one of the most sensitive reaction. $R_{10}$ is an important heat sink and the most sensitive reaction for $S_{u}^{0}$. $R_{2}: \mathrm{OH}+\mathrm{H}_{2}=\mathrm{H}_{2} \mathrm{O}+\mathrm{H}$ significantly contributes to the $\mathrm{OH}$ and $\mathrm{H}$ ROP and to heat release but is not among the most sensitive reactions. Overall, these reactions from the $\mathrm{H}-\mathrm{O}-\mathrm{N}$ system seems to largely dominate the flame dynamics but they are less important for rich mixtures.

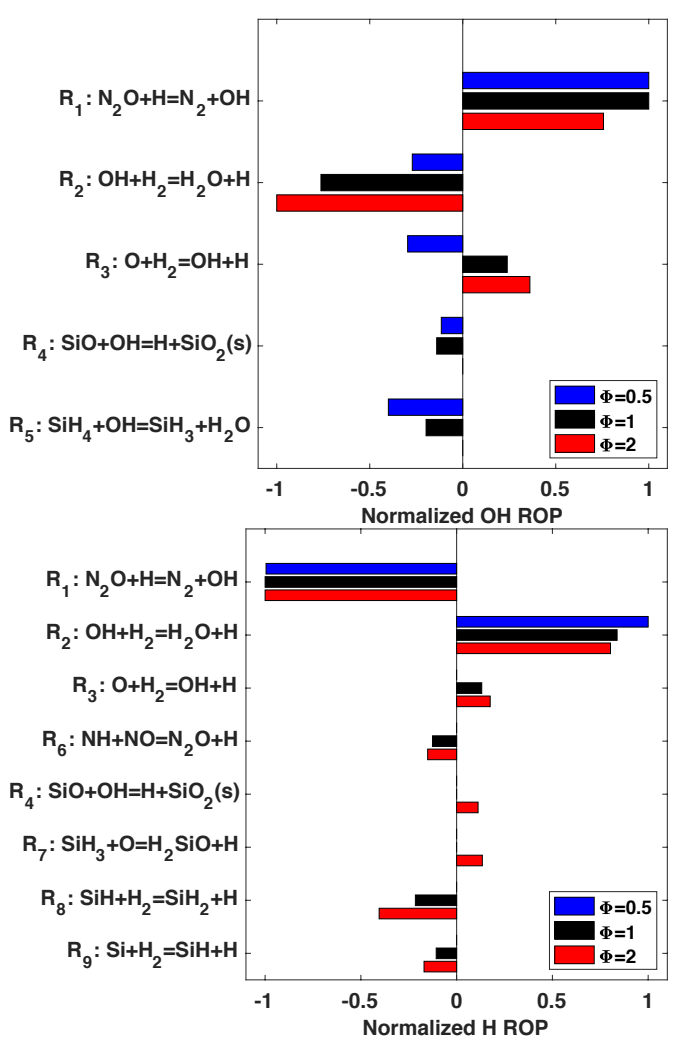

Figure 5: Normalized $\mathrm{OH}$ (top) and $\mathrm{H}$ (bottom) ROP for $\mathrm{SiH}_{4}$ $\mathrm{N}_{2} \mathrm{O}$-Ar flames. $\mathrm{X}_{A r}=0.6 ; \mathrm{T}_{1}=300 \mathrm{~K} ; \mathrm{P}_{1}=51 \mathrm{kPa}$.

Among the reactions forming $\mathrm{SiO}_{x}(\mathrm{~s})$, group (ii), $R_{4}: \quad \mathrm{SiO}+\mathrm{OH}=\mathrm{SiO}_{2}(\mathrm{~s})+\mathrm{H}$ and $R_{11}$ : $2 \mathrm{SiO}=2 \mathrm{SiO}(\mathrm{s})$ are the most important. Except for the $\mathrm{H}$ ROP, the contribution of $R_{4}$ is more important for lean and stoichiometric mixtures, see $\mathrm{OH}$ ROP, HRR, and $C_{S} . R_{11}$ has a higher contribution to HRR in rich mixtures but presents a higher normalized $C_{S}$ for $\Phi=0.5$ and 1 . The most important reactions in group (iii) are $R_{12}: \mathrm{Si}+\mathrm{N}_{2} \mathrm{O}=\mathrm{SiO}+\mathrm{N}_{2}$ and $R_{13}: \mathrm{SiH}_{2}+\mathrm{N}_{2} \mathrm{O}=\mathrm{H}_{2} \mathrm{SiO}+\mathrm{N}_{2} . \quad R_{12}$ is among the two most important reactions for HRR at $\Phi=2$. The importance of $R_{12}$ and $R_{13}$ increases with $\Phi$ 
and both reactions have positive $C_{S}$. On the other hand, $R_{19}: \mathrm{Si}+\mathrm{N}_{2} \mathrm{O}=\mathrm{SiN}+\mathrm{NO}$ demonstrates a negative $C_{S}$ because it competes with $R_{12}$ and forms less reactive species. The pyrolytic reactions of the silicon hydrides, group (iv), become more and more important as $\Phi$ increases. Silane thermal decomposition, $R_{14}: \quad \mathrm{SiH}_{4}+\mathrm{M}=\mathrm{SiH}_{2}+\mathrm{H}_{2}+\mathrm{M}$, constitutes an important heat sink. Nevertheless, it exhibits a positive $C_{S}$ because it enables to produce $\mathrm{SiH}_{2}$ which reacts with $\mathrm{N}_{2} \mathrm{O}\left(R_{13}\right)$, or form $\mathrm{Si}$ atom which also reacts with $\mathrm{N}_{2} \mathrm{O}$ $\left(R_{12}\right)$. Reactions $R_{15}: \mathrm{Si}_{3} \mathrm{H}_{8}=\mathrm{H}_{3} \mathrm{SiSiH}+\mathrm{SiH}_{4}, R_{16}$ : $\mathrm{Si}_{3} \mathrm{H}_{8}=\mathrm{SiH}_{2}+\mathrm{Si}_{2} \mathrm{H}_{6}$, and $R_{17}: \mathrm{Si}_{2} \mathrm{H}_{6}=\mathrm{SiH}_{2}+\mathrm{SiH}_{4}$, which involve $\mathrm{Si}_{3} \mathrm{H}_{8}$ and $\mathrm{Si}_{2} \mathrm{H}_{6}$ have significant HRR contributions but do not appear among the most sensitive reactions. $R_{8}: \mathrm{SiH}+\mathrm{H}_{2}=\mathrm{SiH}_{2}+\mathrm{H}$ essentially proceeds in the backward direction and is an important sink of $\mathrm{H}$ atom, which explains its negative $C_{S}$, despite its exothermicity.

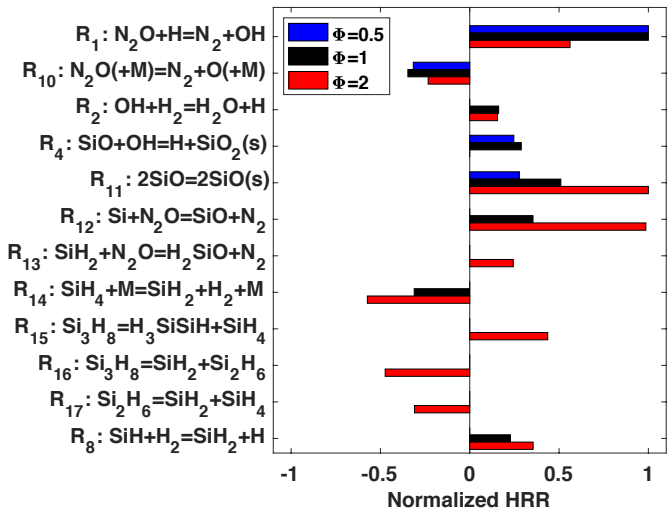

Figure 6: Normalized HRR for $\mathrm{SiH}_{4}-\mathrm{N}_{2} \mathrm{O}-\mathrm{Ar}$ flames. $\mathrm{X}_{A r}=0.6$; $\mathrm{T}_{1}=300 \mathrm{~K} ; \mathrm{P}_{1}=51 \mathrm{kPa}$.

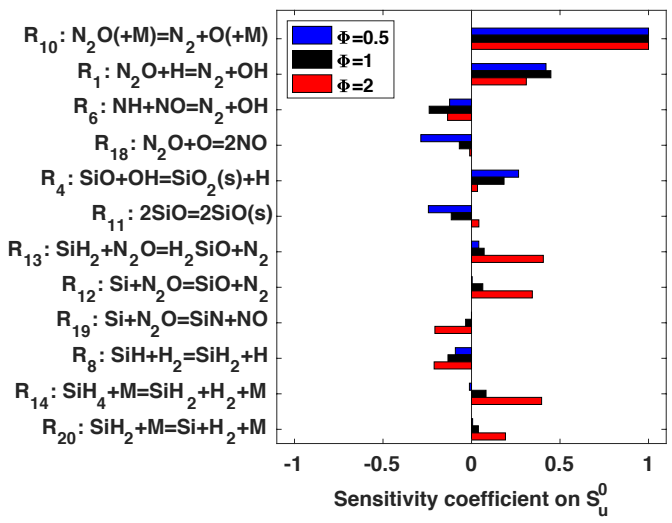

Figure 7: Normalized sensitivity coefficients on $S_{u}^{0}$ for $\mathrm{SiH}_{4}$ $\mathrm{N}_{2} \mathrm{O}$-Ar flames. $\mathrm{X}_{A r}=0.6 ; \mathrm{T}_{1}=300 \mathrm{~K} ; \mathrm{P}_{1}=51 \mathrm{kPa}$.

\subsection{Condensed combustion products}

As the energy released during the formation of condensed combustion products is important for flame propagation in $\mathrm{SiH}_{4}-\mathrm{N}_{2} \mathrm{O}$-Ar mixtures, we performed a number of analyses to characterize them. For mixtures with $\Phi \leq 2$, the powder had an overall white color, while for mixtures with $\Phi \geq 2.2$, the color of the powder appeared rather brownish. Figure 8 shows typical electron micrographs and electronic diffraction patterns obtained at $\Phi=1$ and 2.2. At all $\Phi$, nano-metric spheres were observed as in Fig. 8 top-left, whereas for $\Phi \geq 2$.2, both the spheres and curved nanowires were seen as in Fig. 8 top-right. In all the micrographs, the nanowires were located around the spheres. In the absence of the nanowires, the electron diffraction patterns demonstrated no diffraction features, as in Fig. 8 bottom-left, which is characteristic of an amorphous material. When nanowires were observed, a crystalline structure was demonstrated with the presence of diffraction spots, see Fig. 8 bottom-right. The analysis of the energy-dispersive spectra indicated that the samples contained $\mathrm{Si}$ and $\mathrm{O}$ atoms. In addition to these analyses, XRPD experiments were performed for the samples in which nanowires were present. It indicated that the diffraction pattern corresponds to metal silicon characterized by a cubic structure (lattice parameter: $a=5.425 \AA$ ) with the Fm-3m space group. Providing a detailed explanation of the formation of the nanospheres and nanowires is beyond the scope of the present study and would require additional analyses to better characterize the condensed products. Nevertheless, few comments can be made. At all $\Phi$, the spheres formed correspond to amorphous $\mathrm{SiO}_{x}$ particles whose precise stoichiometry cannot be determined from the analyses made. The highly spherical shape tends to indicate the importance of coalescence in the formation of the particles [34]. This process may be facilitated by the fact that the condensed products are likely in the liquid phase at the flame temperature. The liquefaction temperature of silicon oxide is below $2000 \mathrm{~K}$ [35], which is similar or lower than the flame temperature $\left(\mathrm{T}_{f}\right)$ predicted from constant pressure equilibrium calculations, i.e. at $\mathrm{P}_{1}=51 \mathrm{kPa}, \mathrm{T}_{f}=2024$, 2865 , and $2822 \mathrm{~K}$ for $\Phi=0.3,1.8$, and 2.6, respectively. As commonly done for oxide particles [34], the formation of $\mathrm{SiO}_{x}$ particle is attributed to the clustering/polymerization of monomers, including $\mathrm{SiO}, \mathrm{SiO}_{2}, \mathrm{H}_{2} \mathrm{SiO}$, and $\mathrm{HSiOOH}$, which eventually leads to particle nucleation [23]. At high equivalence ratios, $\Phi \geq 2.2$, silicon nanowires are formed due to the large excess of silane in the reactive mixture. The formation of these nanowires may be attributed to the clustering of cyclic/polycyclic silicon hydrides [36, 37]. Since the silicon nanowires are mostly located around the silica spheres, it might be argued that the spheres could act as a catalytic surface from which the nanowires are growing. In addition, since silicon nanomaterial is 
likely liquid at $\mathrm{T}_{f}$ [38], it could be argued that their formation is taking place after significant cooling of the burned gas has taken place, possibly after flame extinction. Otherwise, a spherical shape of the silicon material would have been favored over the elongated nanowire shape.

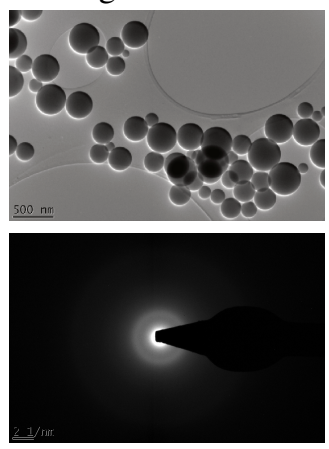

$\Phi=0.98 ; \mathrm{T}_{1}=291 \mathrm{~K}$

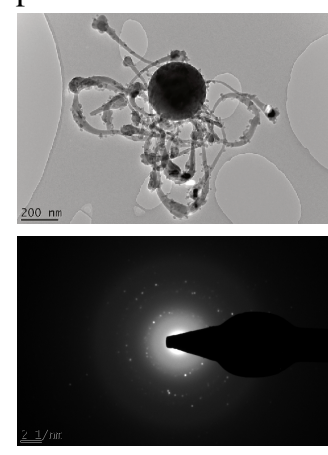

$\Phi=2.20 ; \mathrm{T}_{1}=299 \mathrm{~K}$
Figure 8: Bright field TEM (top) and corresponding SAED (bottom) patterns of particles formed in $\mathrm{SiH}_{4}-\mathrm{N}_{2} \mathrm{O}-\mathrm{Ar}$ flames. $\mathrm{X}_{A r}=0.6 ; \mathrm{P}_{1}=51 \mathrm{kPa}$

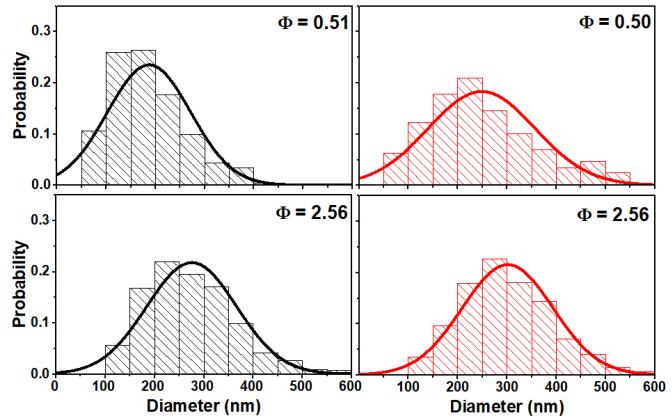

Figure 9: Diameter distribution for spherical particles formed in $\mathrm{SiH}_{4}-\mathrm{N}_{2} \mathrm{O}$-Ar flames. $\mathrm{X}_{A r}=0.6 ; \mathrm{T}_{1}=300 \mathrm{~K} ; \mathrm{P}_{1}=51$ (left) and 101 (right) $\mathrm{kPa}$.

In addition to the analysis of the overall composition and structure of the condensed products, we have characterized the size of the amorphous silicon oxide spheres. Due to the highly convoluted shape of the silicon nanowires, we have not attempted to characterize their dimensions. Figure 9 shows the distribution of diameter of the silica spheres for several $\Phi$. Under all conditions, mono-dispersed distributions were observed. The standard deviation is large since it ranges between 30 and $45 \%$ of the mean diameter, depending on $\Phi$. Figure 10 shows the evolution of the mean diameter with $\Phi$ where the vertical bars correspond to the standard deviation of the particle diameter distribution. Given the large standard deviation, the sphere diameter seems to be relatively independent of the initial mixture composition.

\section{Conclusion}

The present study shows that $\mathrm{SiH}_{4}-\mathrm{N}_{2} \mathrm{O}-\mathrm{Ar}$ mixtures have higher laminar burning rate, explo-

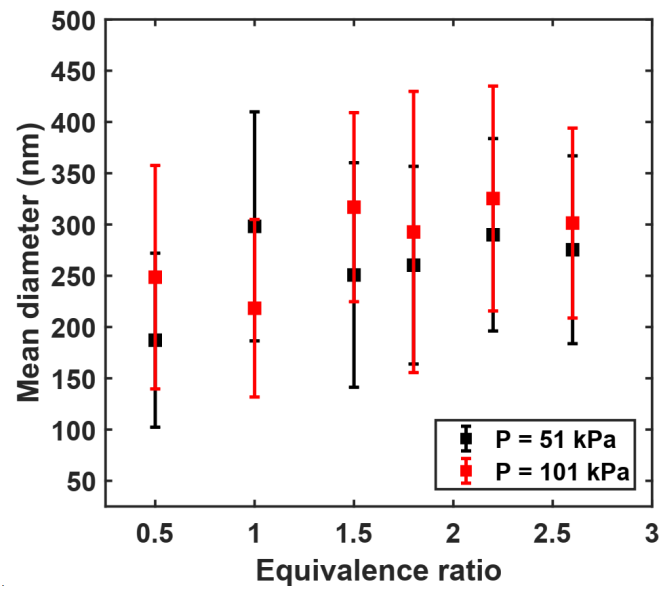

Figure 10: Evolution of the mean diameter with $\Phi$ for spherical particles formed in $\mathrm{SiH}_{4}-\mathrm{N}_{2} \mathrm{O}$-Ar flames. Vertical bars correspond to the standard deviation of the particle diameter distribution. $\mathrm{X}_{A r}=0.6 ; \mathrm{T}_{1}=300 \mathrm{~K}$.

sion peak pressure, and pressure rise coefficient than hydrogen-nitrous oxide and hydrocarbonbased mixtures. Some reactions of the H-O-N system, $R_{1}, R_{2}$, and $R_{10}$ appears important for the flame propagation at all $\Phi$. For rich mixtures, an increased influence of the reactions of the $\mathrm{Si}-\mathrm{H}-\mathrm{O}$ $\mathrm{N}$ system was observed. These latter reactions include: (i) the reactions forming $\mathrm{SiO}_{x}(\mathrm{~s})\left(R_{4}\right.$ and $R_{11}$ ); (ii) the reactions describing the interaction of Si-species with $\mathrm{N}_{2} \mathrm{O}\left(R_{12}\right.$ and $\left.R_{13}\right)$; and (iii) the pyrolytic reactions of the silicon hydrides $\left(R_{8}\right.$ and $\left.R_{14}\right)$. The analysis of the condensed combustion products showed that both silica spherical particles and silicon nanowires were formed during the combustion process. Future work should focus on performing a more detailed characterization of these condensed products to enable a better modeling of the complex chemical dynamics taking place in silane-based flames .

\section{Acknowledgments}

RM was supported by the Thousand Young Talents Program of China. This work was partly supported by the King Abdullah University of Science and Technology, through the baseline fund BAS/1/1396-01-01. The work at Lawrence Livermore National Laboratory was supported by the U.S. Department of Energy and performed under contract DE-AC52-07NA27344.

\section{References}

[1] E. Ngai, R. Fuhrhop, J.R. Chen, J. Chao, C. Bauwens, C. Mjelde, G. Miller, J. Sameth, J. Borzio, M. Telgenhoff, B. Wilson, CGA G-13 large-scale silane release tests - Part I. Silane jet flame impingement tests and thermal radiation measurement, J. Loss Prevent. Proc. 36 (2015) $478-487$. 
[2] J. Chapple-Sokol, C. Giunta, R. Gordon, A kinetics study of the atmospheric pressure CVD reaction of silane and nitrous oxide, J. Electrochem. Soc. 136 (1989) 29933003.

[3] L. Da Silva Zambom, D. Lantin, E. Onoda, P. Verdonck, Non-stoichiometric silicon oxide deposited at low gaseous $\mathrm{N}_{2} \mathrm{O} / \mathrm{SiH}_{4}$ ratios, Thin Solid Films 459 (2004) 220-223.

[4] R. Becerra, H. Frey, B. Mason, R. Walsh, Absolute rate constant and temperature dependence for the reaction of silylene with nitrous oxide, Chem. Phys. Lett. 185 (1991) 415-420.

[5] V. Votintsev, I. Zaslonko, V. Mikheev, V. Smirnov, Mechanism and kinetics of silane decomposition in shock waves, Kinet. Catal. 27 (1987) 972-976.

[6] H. Mick, P. Roth, High-temperature kinetics of $\mathrm{Si}+\mathrm{N}_{2} \mathrm{O}$, J. Phys. Chem. 98 (1994) 5310-5313.

[7] R. Mével, S. Javoy, G. Dupré, A chemical kinetic study of the oxidation of silane by nitrous oxide, nitric oxide and oxygen, Proc. Combust. Inst. 33 (2011) 485-492.

[8] S. Horiguchi, Y. Urano, K. Tokuhashi, S. Kondo, Explosion hazard of silane-nitrogen oxides gas mixture, Koatsu Gasu 26 (1989) 840-847.

[9] G. Thomas, R. Bambrey, G. Oakley, A study of flame acceleration and the possibility of detonation with silane mixtures, Process Saf. Environ. 117 (2018) 278-285.

[10] F. Egolfopoulos, N. Hansen, Y. Ju, K. Kohse-Hoinghaus, C. Law, F. Qi, Advances and challenges in laminar flame experiments and implications for combustion chemistry, Prog. Energy Combust. Sci. 43 (2014) 36-67.

[11] K. Tokuhashi, S. Horiguchi, Y. Urano, M. Iwasaka, H. Ohtani, S. Kondo, Premixed silane-oxygen-nitrogen flames, Combust. Flame 82 (1990) 40-50.

[12] J. Chao, J. Lee, C. Bauwens, S. Dorofeev, Laminar burning velocities of various silanes, J. Loss Prevent. Proc. 36 (2015) 471-477.

[13] V. Babushok, W. Tsang, D. Burgess, M. Zachariah, Numerical study of low- and high-temperature silane combustion, Proc. Combust. Inst. 27 (1998) 2431-2439.

[14] T. Hirano, Accidental explosions of semiconductor manufacturing gases in Japan, J. Loss Prevent. Proc. 17 (2004) 29-34.

[15] R. Mével, F. Lafosse, N. Chaumeix, G. Dupré, C.E. Paillard, Spherical expanding flames in $\mathrm{H}_{2}-\mathrm{N}_{2} \mathrm{O}$-Ar mixtures: Flame speed measurement and kinetic modeling, Int. J. Hydrog. Energy 34 (2009) 9007-9018.

[16] Z. Chen, On the extraction of laminar flame speed and Markstein length from outwardly propagating spherical flames, Combust. Flame 158 (2011) 291-300.

[17] S. Javoy, R. Mével, G. Dupré, Oxygen atom kinetics in silane-hydrogen-nitrous oxide mixtures behind reflected shock waves, Chem. Phys. Lett. 500 (2010) 223-228.

[18] R. Mével, S. Javoy, F. Lafosse, N. Chaumeix, G. Dupré, C.E. Paillard, Hydrogen-nitrous oxide delay time: shock tube experimental study and kinetic modelling, Proc. Combust. Inst. 32 (2009) 359-366.

[19] S. Kondo, K. Tokuhashi, A. Takahashi, M. Kaise, A numerical study of low temperature silane combustion, Combust. Sci. Technol. 159 (2000) 391-406.

[20] T. Miller, M. Wooldridge, J. Bozzelli, Computational modelling of the $\mathrm{SiH}_{3}+\mathrm{O}_{2}$ reaction and silane combustion, Combust. Flame 137 (2004) 73-92.

[21] E.L. Petersen, D.M. Kalitan, M.J.A. Rickard, M.W. Crofton, Silane oxidation behind reflected shock waves, in: Z. Jiang (Ed.), Shock waves, Springer, Berlin, 2005, pp. 585-590.

[22] H. Mick, H. Matsui, P. Roth, High-temperature kinetics of $\mathrm{Si}$ atom oxidation by $\mathrm{NO}$ based on $\mathrm{Si}, \mathrm{N}$, and $\mathrm{O}$ atom measurements, J. Phys. Chem. 97 (1993) 6839-6842.

[23] S.M. Suh, M. Zachariah, S. Girshick, Modeling particle formation during low pressure silane oxidation: detailed chemical kinetics and aerosol dynamics, J. Vac. Sci. Technol. A 19 (2001) 940-951.

[24] A. Konnov, Detailed reaction mechanism for small hydrocarbons combustion. release 0.5., 2000.

[25] M. Donovan, D. Hall, P. Torek, C. Schrock, M. Wooldridge, Demonstration of temperature and $\mathrm{OH}$ mole fraction diagnostic in $\mathrm{SiH}_{4} / \mathrm{H}_{2} / \mathrm{O}_{2} / \mathrm{Ar}$ flames using narrow-line UV OH absorption spectroscopy, Proc. Combust. Inst. 29 (2002) 2635-2643.

[26] H. Pitsch, URL: http://www. itv. rwth-aachen. de/en/downloads/flamemaster (1998).

[27] K.L. Chatelain, R. Mevel, D.A. Lacoste, Correction of reaction models using collision limit violation analyses: application to a silane reaction model, Combust. Flame 217 (2020) $346-359$.

[28] D.G. Goodwin, H.K.. Moffat, R.L. Speth, Cantera: An Object-oriented Software Toolkit for Chemical Kinetics, Thermodynamics, and Transport Processes, 2005.

[29] H.J. Mick, P. Roth, V.N. Smirnov, I.S. Zalonko Formation of hydrogen atoms in silane pyrolysis behind shock waves. Kinetics and thermochemistry of $\mathrm{SiH}_{4}, \mathrm{SiH}_{3}$, and $\mathrm{SiH}_{2}$ decomposition, Kinetics and Catalysis 35 (1994) $485-497$.

[30] S. Lapointe, R. Whitesides, M. McNenly, Sparse, iterative simulation methods for one-dimensional laminar flames, Combust. Flame 204 (2019) 23 - 32.

[31] L. Zhang, H. Ma, Z. Shen, L. Wang, R. Liu, J. Pan, Influence of pressure and temperature on explosion characteristics of n-hexane/air mixtures, Exp. Therm. Fluid Sci. 102 (2019) $52-60$.

[32] S.P.M. Bane, R. Mével, S.A. Coronel, J.E. Shepherd, Flame burning speeds of undiluted and nitrogen diluted hydrogen-nitrous oxide mixtures, Int. J. Hydrog. Energy 36 (2011) 10107-10116

[33] F. Tamanini, J. Chaffe, R. Jambar, Reactivity and ignition characteristics of silane/air mixtures, Process Saf. Prog. 17 (1998) 243-258.

[34] M. Wooldridge, Gas-phase combustion synthesis of particles, Prog. Energy Combust. Sci. 24 (1998) 63-87.

[35] National Institute for Occupational Safety and Health, NIOSH pocket guide to chemical hazards, Technical Report, Department of Health and Human Services, 2005.

[36] M. Swihart, S. Girshick, Thermochemistry and kinetics of silicon hydride cluster formation during thermal decomposition of silane, J. Phys. Chem. B 103 (1999) 64-76.

[37] M. Swihart, S. Girshick, Ab initio structures and energetics of selected hydrogenated silicon clusters containing six to ten silicon atoms, Chem. Phys. Lett. 307 (1999) 527-532.

[38] M. Caninenberg, E. Verheyen, D. Kiesler, B. Stoib, M. Brandt, N. Benson, R. Schmechel, Sample temperature profile during the excimer laser annealing of silicon nanoparticles, Opt. Laser Technol. 74 (2015) 132-137. 